ELUA

ISSN 2171-6692

Núm. 35, 2021, págs. 163-178

https://doi.org/10.14198/ELUA2021.35.8

\title{
EL CONDICIONAL PERIODÍSTICO EN LOS TITULARES DE PRENSA EN HABLA HISPANA
}

\author{
THE JOURNALISTIC CONDITIONAL IN SPANISH-SPEAKING NEWS \\ HEADLINES
}

\author{
Silvia HurTado GonzÁlez \\ Universidad de Valladolid, España \\ silvia.hurtado@uva.es \\ https://orcid.org/0000-0002-9206-7688
}

\begin{abstract}
Resumen
El objetivo de este trabajo es el análisis del condicional periodístico en el ámbito de la titulación en la prensa escrita hispanohablante. Este condicional plantea una serie de cuestiones, de diferente calado, no siempre fáciles de responder. Después de resumirlas, nos detenemos en la explicación del marco teórico siguiendo a Vatrican (2016). Posteriormente, se justifica la metodología adoptada y se explica el proceso seguido para el análisis del corpus, tras lo cual se ofrecen los resultados de la expurgación de los 360 titulares examinados, pertenecientes a artículos informativos de nueve diarios digitales de habla hispana durante los meses de febrero a mayo de 2010. Se registran casos de condicional periodístico en todos los periódicos seleccionados (siquiera en su forma simple), aunque con variaciones geográficas de interés. Una vez presentados los datos cuantitativos, se lleva a
\end{abstract}

\begin{abstract}
The objective of this work is to analyze the journalistic conditional in Spanish-speaking press headlines. This conditional proposes a series of questions, at distinct levels, which are not always easy to answer. After summarizing them, we offer an explanation of the theoretical framework, according to Vatrican (2016). Then, the adopted methodology is justified, explaining the process followed to analyze the body of work. Next, we present the results of the compiling of the 360 examined headlines, all of which are news articles from nine online newspapers between February and May of 2010. Cases of the journalistic conditional are found in all of the selected newspapers (even in its simple form), although noteworthy geographic variations are evident. Once the quantitative data have been presented, a comparison is made of the distinct headlines with the jour-
\end{abstract}

Para citar este artículo: Hurtado González, Silvia (2021). El condicional periodístico en los titulares de prensa en habla hispana. ELUA, 35: 163-178. https://doi.org/10.14198/ELUA2021.35.8

Recibido: 03/04/2020, Aceptado: 26/10/2020

(C) 2021 Silvia Hurtado González

Este trabajo está sujeto a una licencia de Reconocimiento 4.0 Internacional

de Creative Commons (CC BY 4.0) 
cabo una comparación entre distintos titulares con condicional periodístico y se examina su funcionamiento discursivo.

PALABRAS CLAVE: titulares; prensa; condicional periodístico; rumor; evidencialidad. nalistic conditional, examining their discursive functioning.

KEYWORDS: headlines; press; journalistic conditional; rumor; evidentiality.

\section{INTRODUCCIÓN}

Si bien contamos ya con un considerable número de investigaciones centradas en diversas cuestiones sintácticas, semánticas y pragmáticas del titular, se echan en falta estudios detallados y empíricos en torno al condicional periodístico en la prensa digital de habla hispana. Cubrir en parte esta laguna es la finalidad del presente trabajo, que gira en torno a este uso verbal en la titulación de los diarios españoles e hispanoamericanos.

Por lo tanto, el objetivo de estudio del presente trabajo es el titular, que, como es bien sabido, es el elemento clave en la configuración discursiva del texto informativo, reducido habitualmente en la prensa digital al título, única parte imprescindible de la titulación que, en este tipo de periódicos, funciona, además, como hipervínculo de la noticia ${ }^{1}$.

Desde un punto de vista cuantitativo, el interés se centra en el estudio del empleo del condicional periodístico en diarios pertenecientes a variedades diferentes del ámbito hispánico, poniendo en relación nuestros resultados con los escasos datos disponibles hasta el momento. Desde un punto de vista cualitativo, ofrecemos el análisis de ejemplos representativos en los que se ponen de manifiesto los aspectos más destacados en torno al uso del condicional periodístico. En el último apartado de las conclusiones, hacemos un recuento de los principales hallazgos de esta investigación.

\section{PROBLEMAS PLANTEADOS EN TORNO AL CONDICIONAL PERIODÍSTICO}

La denominación tradicional de este condicional es condicional de rumor. Sin embargo, este nombre presenta algunos inconvenientes que tienen que ver con lo que evoca la palabra rumor. Según Bermúdez, este término sugiere que "se trata de información que no es de primera mano y además de origen desconocido o, al menos, no explícito" (Bermúdez 2016: 44). Sin embargo, como señala este autor, esta suposición no es del todo cierta, ya que la fuente de información puede estar explícita en el propio titular o en el contexto inmediato, lo que ilustra con el siguiente ejemplo:

(1) Nols estaría considerando, según el propio Le Pen, la creación en Bélgica de un Frente Nacional de extrema derecha, similar al francés. (El País, 01/10/1984)

La pregunta que se hace Bermúdez (2016) en este punto es si solamente puede hablarse de rumor cuando la fuente es inespecífica o bien se considera también rumor cuando se reconoce una fuente directa más o menos explícita. Para este investigador, se trata, en el fondo, de "a qué se llama rumor" (Bermúdez 2016: 44), un asunto de gran importancia "con

1 Aunque no desconocemos la distinción entre los términos titular y título que se realiza en los ámbitos especializados, en este estudio hemos optado por considerar ambas expresiones como equivalentes. 
largos antecedentes en el discurso periodístico aunque ha merecido escasa atención y acaso el condicional no sea su mayor exponente" (Brunetti 2016: 113).

Sin embargo, aun cuando la denominación condicional de rumor no resulta la más adecuada, se sigue utilizando y es la más popular. Por poner un ejemplo, es la que emplea la Nueva gramática de la lengua española de La Real Academia Española y la Asociación de las Academias de la Lengua (en adelante, $N G L E$ ) de 2009. Otros autores, como Vatrican (2016), Brunetti (2016), Bermúdez (2016) o García Negroni (2018) alternan indistintamente esta designación tradicional con la de condicional periodístico, empleada ya por Veiga (1991), con la que se pretende evitar el término problemático (rumor) y con la que se alude al registro o discurso en el que este condicional aparece con mayor frecuencia, cuestión sobre la que volveremos más adelante. Pero la lista de términos para nombrar a este condicional es más larga: condicional de información no asegurada (Lapesa 1977), condicional de alteridad (Foullioux 2006), potencial citativo (Nadal Palazón 2012), condicional citativo (Reyes 1994; Azzopardi 2013) o condicional epistémico de atribución (Kronning 2015).

No obstante, al margen del nombre elegido, el condicional periodístico plantea otras cuestiones, en varios niveles, no siempre fáciles de responder, al menos de momento, como su supuesto origen tardío y espurio en el español y su consideración normativa, aspectos que se encuentran claramente relacionados, aunque en los últimos años se han ido relativizando y matizando.

En cuanto a su origen, si bien Azzopardi (2013) sostiene que el condicional periodístico "aparece en español en el siglo XVIII" (Azzopardi 2013: 343), cuando se publican los primeros periódicos en España, se considera, por lo general, que es un fenómeno del siglo XX. Pero Kronning (2015), quien lleva a cabo una investigación en Google Libros (1500-1900) en torno a las formas estaría / habría estado en combinación con según X, encuentra la primera certificación del condicional epistémico de atribución, como él llama al condicional que nos ocupa, en la traducción de una obra científica francesa del año 1848: su grado de espesor estaría, según Bichat, en correlación con las paredes abdominales, aunque atestigua asimismo su presencia en textos originales de la misma época, como el siguiente, de 1857: El oso común que, según Zimmermann, estaría difundido por todo el globo, no existe en América, y parece no haber dejado la Europa y el Norte de África.

Kronning (2015) sostiene que el hecho de que el más antiguo de estos casos de condicional aparezca en una traducción del francés, "apoya provisionalmente la idea de que es un galicismo en español” (Kronning 2015: 516), si bien tampoco excluye la posibilidad de que se haya tomado directamente del italiano e, incluso, sugiere que puede ser el resultado de una poligénesis románica. Sin embargo, hay que señalar que este mismo autor, mediante una búsqueda en el CORDE (Corpus diacrónico del español), identifica varios ejemplos en el español del siglo XVI que "son o parecen ser" (Kronning 2014: 83-84) ejemplos de condicional epistémico de atribución, lo que llevaría a cuestionar indirectamente el hecho de que se trate de un galicismo, dado que, como observa Bermúdez, "si este uso existe en la lengua castellana desde fecha tan antigua, y en diferentes tipos de discurso, podría afirmarse que es un rasgo que pertenece al castellano por derecho propio" (Bermúdez 2016: 42). Obviamente, para realizar afirmaciones tajantes sobre el origen de este condicional, hacen falta estudios diacrónicos que se ocupen en profundidad del origen de este uso.

Precisamente uno de los argumentos a los que se acudía para cuestionar la corrección del condicional periodístico era su condición de extranjerismo. Al decir de Lázaro Carreter 
(2001: 386), es “puro francés”, mientras que Gili Gaya (1943: \#129) duda en calificarlo como galicismo o como anglicismo. En la actualidad, las interdicciones normativas han llegado a su fin, ya que, en la última gramática académica (NGLE, 2009), se legitima el empleo de este condicional al considerarlo como una variante del condicional de conjetura, idea, por otra parte, ya adelantada por Gili Gaya (1943: \# 129).

El hecho de que este condicional no violente los valores de la forma en -ría es, sin duda, el factor clave para su reconocimiento normativo, como se pone de manifiesto en la siguiente cita:

[L]o único que ha hecho esta forma verbal es sumar un nuevo valor a las múltiples nociones que ya transmitía. Los hablantes - o, más concretamente, los periodistas - han optado por "sacarle más partido" al condicional y emplearlo con un valor que antes no tenía cabida en el sistema verbal. Para expresar esta noción, en lugar de recurrir, como otras veces, a una combinación de verbos, es decir, a una perífrasis, se ha preferido remodelar el paradigma. Dado que el nuevo significado era muy cercano a otro que ya poseía el condicional (el de conjetura: Serían las doce cuando llegó), la reforma suponía una obra menor que permitía, en definitiva, aprovechar mejor aquello con lo que ya se contaba (Borrego Nieto 2016: 269-270).

En efecto, como ya hemos adelantado, en la NGLE (2009) se explica que el condicional de rumor es la variante del condicional de conjetura "que se usa a menudo en el lenguaje periodístico para presentar las informaciones de forma cautelosa o dar noticias no suficientemente contrastadas" (NGLE 2009: \#23.15m), variante en la que coinciden la forma simple y la compuesta. Por otra parte, esta gramática, al tratar del uso modalizado de las formas verbales, reconoce su valor citativo. Aquí destaca que este condicional sirve también "para relativizar la veracidad de la información que se presenta atribuyéndosela a otros" (NGLE 2009, \#25.1f). Es decir, al final, en esta obra se hipotetizan dos valores para el condicional de rumor o periodístico: la presentación de información no asegurada y la alusión a un discurso ajeno. En términos generales, estos dos valores aparecen recogidos en los estudios que, desde distintos marcos teóricos, central o tangencialmente, se ocupan de este tipo de condicional.

Sin embargo, a pesar de haberse reconocido la corrección normativa de este empleo desde el punto de vista gramatical, el uso de este condicional sigue planteando problemas que afectan a la calidad de la información. La principal razón del repudio a este condicional es que "el rumor no debe ser presentado como noticia" (NGLE 2009, \# 23.15m). Ahora bien, Brunetti (2016), en la línea de lo apuntado por Bermúdez (2016) al inicio de este apartado, se pregunta: “¿Qué rumores? Este es el punto más controvertido” (Brunetti, 2016, 111). Pero Brunetti (2016) va más lejos, ya que, a través de diversos deslindes, precisiones y contextualizaciones, intenta contrarrestar la "mala reputación en el ámbito periodístico" (Brunetti 2016: 108) de este tipo de condicional. Así, esta autora demuestra que el condicional no siempre está vinculado a rumores y que la publicación de informaciones no confirmadas no contraviene, en ocasiones, normas periodísticas (Brunetti, 2016, 110)2.

2 Brunetti (2016) explica el histórico "fallo Campillay" o "doctrina Campillay" (Campillay, Julio César c/ La Razón y otros. 15/5/1986). Los diarios argentinos Popular, Crónica y La Razón publicaron un comunicado de la Policía Federal, sin mencionar la fuente, en el que se involucraba a Julio Campillay en la comisión de diversos delitos. Posteriormente, fue sobreseído definitivamente en la sede penal. Campillay demandó a los periódicos citados por daño moral alegando que, al relacionarlo falsamente con robos, drogas y armas, se puso en duda 


\section{FUNDAMENTACIÓN TEÓRICA}

El objetivo de este apartado es deslindar los usos y funciones del condicional periodístico siguiendo el marco teórico de Vatrican $(2016)^{3}$, uno de los estudios más acertados, en nuestra opinión, en este ámbito. Esta autora proporciona una descripción minuciosa del condicional en español, por lo que tiene que ocuparse del condicional periodístico y de las herramientas necesarias para poder identificarlo, comparando, cuando es preciso, los distintos usos entre sí.

Hay que comenzar señalando que el condicional es una forma verbal que presenta valores temporales y valores modales. El condicional temporal no constituye, según Vatrican (2016), una clase homogénea, sino que puede subdividirse en tres grupos ${ }^{4}$ : el discurso indirecto estándar (Dijo que él lo haría), el discurso indirecto libre (De ninguna manera aceptaría la ruptura) y el condicional histórico o narrativo (En 1492 Colón descubriría América).

Pero, junto a los valores temporales rectos, determinadas formas verbales, entre ellas el condicional, pueden presentar una alteración en el significado temporal. Se trata de los valores dislocados o desplazados, esto es, modales (Rojo y Veiga 1999: 2894, 2913). El ser modal ha recibido un número amplísimo de definiciones, pero solo vamos a citar la de la NGLE (2009) para la que el significado de cada uno de estos condicionales modales "se obtiene subordinando implícitamente sentidos temporales a algún predicado de naturaleza epistémica que denota probabilidad, suposición u otras nociones semejantes que relativizan (o convierten en dependiente) el estado de cosas que se considera" (NGLE 2009, \#25.1f).

Vatrican (2016) menciona cuatro condicionales modales: el condicional no factual hipotético (Si hablaras con él, se arreglarían las cosas), el condicional de cortesía/atenuación (De buena gana me tomaría un café), el condicional de conjetura (En aquella época, Juan tendría unos 40 años) y el condicional de rumor/periodístico (Se trataría, según estas fuentes, de falsas facturas). Y forma con ellos dos grupos: el primero abarca el no factual y el de cortesía/atenuación, mientras que el segundo contiene el de conjetura y el de rumor/ periodístico. Por lo tanto, esta autora no considera, a diferencia de la NGLE (2009), que el condicional de rumor sea una variante del de conjetura.

Es preciso caracterizar aquí lo más detalladamente posible el condicional de rumor o periodístico, requisito previo para su correcta identificación en el corpus. Para ello, Vatrican (2016) acude a la modalidad epistémica y a la noción de evidencialidad.

En primer lugar, expone esta autora que el condicional periodístico presenta un valor epistémico porque "introduce una situación cuya veracidad no se asegura y con la que no se compromete el hablante" (Vatrican, 2016: 76), como se pone de manifiesto en el siguiente ejemplo:

su reputación. La Suprema Corte de Justicia de Argentina sentó entonces las bases que permiten excusar la responsabilidad del periodista cuando se atribuya el contenido informativo a la fuente pertinente, se utilice un tiempo verbal potencial o se deje en reserva la identidad de los implicados en la publicación. Consecuentemente, "para los casos en los que una noticia atribuye a un individuo hechos delictivos, el condicional se ha propuesto como una categoría apropiada para la información" (Brunetti 2016: 111). Sin embargo, pueden darse casos más complejos que, aunque estén amparados por la norma, plantean controversia (véase Brunetti 2016: 112-113). Al final, este condicional no vale para todo, puesto que, en algunas noticias, se puede interpretar como resultado de una actitud sesgada en la información. "Es en este sentido en el que el condicional al menos se presta a un juego malicioso, lo que significa que su uso está ligado al tema de que trate la información y este territorio exige precaución" (Brunetti 2016: 113).

3 Las ideas más importantes que se desarrollan en este trabajo de Vatrican (2016) ya habían sido apuntadas en un anterior trabajo (Vatrican 2014).

4 Todos los ejemplos reproducidos en esta sección pertenecen a Vatrican (2016). 
(1) Se trataría, según estas fuentes, de "falsas facturas" y de "documentos indebidos" vendidos a "personalidades políticas" o del show business. (El Mundo, 14/10/14)

Esto también es posible con la forma compuesta:

(2) El presidente de Andorra se habría reunido con bancos implicados en el caso Pujol. (La sexta.com, 14/08/2014)

El ejemplo con el condicional simple se entiende como "es probable que se trate de falsas facturas y documentos indebidos" y el enunciado con condicional compuesto como "es probable que el presidente de Andorra se haya reunido con bancos implicados en el caso Pujol" (Vatrican 2016: 76).

Pero, por otra parte, este tipo de condicional presenta un valor evidencial porque deja entrever la naturaleza de la fuente de información, que, en este caso, procede de otra fuente distinta al hablante. Volviendo a los ejemplos anteriores, el enunciado con condicional simple equivale a "dicen que se trata de falsas facturas pero no puedo asegurarlo" y en el segundo, con condicional compuesto, a "dicen que el presidente de Andorra se ha reunido con bancos implicados en el caso Pujol pero no puedo asegurarlo" (Vatrican 2016: 76).

Tras esta presentación del condicional periodístico, examina con más detenimiento cómo aparecen estas dos características. En primer lugar, se ocupa de la expresión de la modalidad epistémica. Así, señala que este condicional expresa la modalidad epistémica de posibilidad (concretamente, de probabilidad), "porque la modalidad opera sobre una proposición, de acuerdo con lo que sabe el hablante" (Vatrican 2016: 77). Esto es, el hablante expresa cierta duda con respecto a la situación que describe, característica que comparte con el condicional de conjetura.

Con el fin de explicar este punto, Vatrican recurre, entre otros, al siguiente ejemplo:

(3) Sevilla tendría próximamente carrera de psicología para los jóvenes que deseen estudiar esta carrera en el municipio. (Canal Vivavisión, 08/07/2014)

Se entiende que es muy probable que Sevilla tenga en el futuro esta carrera. Aunque, como señala Vatrican (2016), este condicional podría leerse como un condicional no factual, añadiendo una prótasis implícita en la frase, si se añade esta, no se obtiene la lectura propia del condicional de rumor, sino otro enunciado con distinto significado, como se observa si modificamos el anterior ejemplo:

(4) Sevilla tendría carrera de psicología, si la Junta de Andalucía lo aceptara.

Para esta investigadora, este hecho es extensivo a la forma compuesta, de manera que el anterior ejemplo (2) no equivale al siguiente con una prótasis explícita:

(5) El presidente de Andorra se habría reunido con bancos implicados en el caso Pujol, si no hubiera tenido otro viaje oficial a Francia.

Es más, en esta paráfrasis se infiere que el presidente de Andorra no se ha reunido con los bancos, es decir, significa justamente lo contrario de lo que se quiere expresar.

Hechas estas aclaraciones, Vatrican (2016) sostiene que la hipótesis más convincente es la defendida por autores como Lapesa (1977), Casado Velarde (1995) o Ridruejo (1979), según 
la cual el condicional periodístico puede subordinarse a una prótasis que se relaciona con la fuerza ilocutiva de la frase, esto es, con una condición del tipo "si se confirma el rumor, si esto es cierto" (Vatrican 2016: 79). Este condicional, por consiguiente, "no se subordina a la realización de una situación sino a la verdad de lo que se asevera" (Vatrican 2016: 79).

Después de esta descripción de la modalidad epistémica, Vatrican se detiene en explicar qué tiene de evidencial el condicional periodístico, porque este, a diferencia del condicional de conjetura, es evidencial ${ }^{5}$ en el sentido antes adelantado de que permite significar que el hablante transmite una información ajena; por eso puede ser sustituido fácilmente por dicen que o supuestamente.

Por lo tanto, esta autora, siguiendo a Aikhenvald (2004), considera el condicional periodístico como una estrategia de la evidencialidad indirecta de tipo reportativo: "la información no se ha adquirido de forma directa (percepción, por ejemplo), sino de forma indirecta: alguien que no es el hablante dice que, rumorea que" (Vatrican 2016: 81).

Un dato importante es que la fuente de la información puede estar asimismo explícita en la frase sin que se altere su valor evidencial:

(6) El PNV ganaría las elecciones autonómicas del País Vasco el próximo 21 de octubre, al obtener 27 de los 75 escaños del Parlamento, según una encuesta electoral que publica hoy el Centro de Investigaciones Sociológicas (CSI). (Europa Press, 05/10/2012)

Es en este momento cuando Vatrican (2016) aborda una de las mayores dificultades a la hora de analizar este uso del condicional: la relación existente entre la modalidad epistémica y la evidencialidad. Para solventar este problema, formula la hipótesis de que el condicional periodístico expresa una información dudosa, mientras que el condicional de conjetura expresa un hecho dudoso. En el primer caso, tiene alcance sobre la verdad del decir, es decir, sobre la fuerza ilocutiva. En el segundo caso, la probabilidad actúa sobre la realización de un hecho del mundo real. Para explicarlo, retoma un ejemplo anterior, reproducido nuevamente aquí para mayor claridad:

(7) Sevilla tendría próximamente carrera de psicología para los jóvenes que deseen estudiar esta carrera en el municipio. (Canal Vivavisión, 08/07/2014)

En este enunciado, según Vatrican (2016), se habla de la probabilidad de que el rumor según el cual Sevilla va a tener carrera de psicología sea verdad. "Hablamos de lo dicho" (Vatrican 2016: 84). Y este significado no es el mismo que el que presenta el condicional de conjetura en el siguiente ejemplo:

(8) En aquella época, Juan tendría unos 40 años.

Sin embargo, en esta oración, se está hablando de la probabilidad de que la situación "Juan tenía unos 40 años en aquella época" se haya dado. "Hablamos de lo ocurrido" (Vatrican 2016: 84).

5 La evidencialidad es el dominio semántico relacionado con la expresión de la fuente de información presentada en el enunciado y representa el modo en que el locutor señala cómo ha adquirido la información que quiere comunicar. El efectivo alcance de este dominio y su relación con otros dominios relacionados es hoy uno de los puntos más debatidos en las discusiones sobre el tema. 
Finalmente, para identificar los casos de condicional periodístico, advierte esta estudiosa que también es necesario considerar el enfoque temporal del predicado verbal y la persona que se usa. En cuanto al enfoque temporal, señala que es de presente o de futuro para la forma simple y de pretérito compuesto para la forma compuesta, a diferencia del condicional de conjetura, que solo tiene enfoque de pasado. Y, si el condicional periodístico aparece en contextos de subordinación, el verbo de la principal ha de ser presente, como en el siguiente ejemplo:

(9) La última [encuesta], elaborada por el Instituto CSA y difundida la semana pasada por Le Figaro, señala que la ultraderecha y la derecha se disputarian los escaños en la segunda vuelta en 359 de las 577 circunscripciones existentes. ( El Pais, 08/12/2014)

Respecto al otro parámetro de identificación, Vatrican (2016) hace notar que "el condicional de rumor por lo general exige el uso de la tercera persona" (Vatrican 2016: 86), tal como se ha podido comprobar en los ejemplos anteriores (Vatrican 2016: 86).

\section{CONSIDERACIONES METODOLÓGICAS}

\subsection{Delimitación del corpus}

Se viene señalando que el condicional periodístico (de ahí su nombre) es propio de un género en particular: el discurso informativo de los medios de comunicación. Además, hay acuerdo en considerar que, dentro de este tipo de textos, es más característico de una determinada fracción de la noticia: el titular. Nadal Palazón (2012), por ejemplo, en su estudio sobre las características lingüísticas de los titulares en habla hispana, lo clasifica como uno de los rasgos, aunque variables, de este espacio periodístico privilegiado, es decir, como una peculiaridad de los titulares, aunque con una distribución menos regular que otros rasgos que él cataloga como constantes. Pero, como señala Brunetti (2016: 110), ni todos los usos del condicional en la prensa pueden ser considerados como condicionales periodísticos ni son exclusivos de este género. En consonancia con las palabras de esta estudiosa, Kronning señala que este valor "no se encuentra en absoluto restringido a este tipo de discurso" (Kronning 2015: 509). Así, sin negar que sea propio de los géneros periodísticos, sostiene, basándose en un corpus de ejemplos de 2002, que es típico también de otro hipergénero: el discurso histórico y científico. "De hecho, es fácil verificar la aparición de este condicional en este tipo de discurso, como por ejemplo, la historia, la geología o la antropología" (Kronning 2015: 509).

Hay que advertir que este autor unifica los usos periodísticos y los científicos e históricos (y aun los literarios ${ }^{6}$ ) destacando que lo primordial es que en todos estos hipergéneros la información es atribuida a una fuente externa, sea específica o no, sea de segunda o de tercera mano. Pero la pregunta que se plantea ahora es si estos usos del condicional son meras variantes de un mismo fenómeno o si se trata de tipos diferentes, lo que vendría a alterar el panorama expuesto hasta el momento. Según Bermúdez (2016), "hay ciertas razones para creer que, al menos en español, se trata de dos fenómenos en parte diferentes" (Bermúdez 2016: 60). Este autor, a partir de una visión de la evidencialidad basada en el modelo de la

6 Según Kronning, "aunque especialmente característico de los géneros de discurso periodístico, histórico y científico, no es del todo inusual en el discurso literario" (Kronning 2015: 516-517), aunque, teniendo en cuenta sus datos, esta afirmación solo puede aplicarse al español latinoamericano. 
deixis espacial (Bermúdez 2006), establece ciertas diferencias entre el condicional periodístico (El primer ministro renunciaría en las próximas horas) y el condicional típico del discurso científico (juventud sería el lapso que media entre la madurez física y la madurez social), originadas por manifestar diferentes propiedades evidenciales. Bermúdez (2016) propone que el condicional científico expresa información de segunda mano y modo de acceso cognitivo, mientras que el periodístico es un marcador de información de tercera mano.

Argumenta Bermúdez que "si se tratara del mismo fenómeno, sería improbable que la reacción normativa solo se hubiera producido contra los casos aparecidos en el discurso periodístico" (Bermúdez 2016: 61). Asimismo, sostiene que el condicional científico "se encuentra conceptualmente cerca del circunstancial hipotético, y puede pensarse que se deriva de este" (Bermúdez 2016: 61), lo que explicaría, en su opinión, las características mencionadas que lo diferencian del condicional periodístico.

Por otra parte, García Negroni (2018), en el marco del enfoque dialógico de la argumentación y la polifonía de Ducrot, propone que el condicional periodístico y el condicional científico plasman puntos de vista evidenciales que, como tales, exigen recuperar un marco de discurso previo que se muestra como la causa de la enunciación en la que esos puntos de vista evidenciales se expresan. Determinados por el género discursivo en el que se inscriben los enunciados con condicional periodístico y con condicional científico, los distintos marcos de discurso previos que ellos instan a recuperar son precisamente los que permiten explicar las diferencias de sentido que surgen de las enunciaciones periodísticas y las enunciaciones científicas.

Dejando de lado esta cuestión, que excede los objetivos del presente trabajo, el hecho de que el condicional que nos ocupa esté asociado (y eso nadie lo pone en duda) a los textos periodísticos ha determinado la selección del material que conforma el eje central de nuestra investigación.

\subsection{Formación del corpus}

Para conformar el corpus objeto de estudio, se examinó una muestra no probabilística constituida por 360 artículos informativos pertenecientes a diferentes secciones temáticas durante los meses de febrero a mayo de 2010. En concreto, la muestra analizada se compone de la suma de 40 noticias procedentes de cada uno de los siguientes periódicos de habla hispana en su versión electrónica: El País y El Mundo (de España), El Universo (de Ecuador), El Nacional (de Venezuela), La República (de Perú), El Mercurio (de Chile), El Tiempo (de Colombia), La Nación (de Argentina) y El Universal (de México). Los diarios fueron elegidos teniendo en cuenta los siguientes parámetros considerados relevantes: compartir determinados rasgos de formalidad y representar el mismo nivel de lengua. De esta manera se pretendía asegurar la homogeneidad de la muestra.

Por otra parte, se ha creído conveniente analizar la prensa en línea por ser la que más ha proliferado en los últimos años y porque es en ella donde tiene mayor incidencia el fenómeno de la inmediatez, característico de los medios de comunicación. Son los periodistas que trabajan en estos medios los que más se enfrentan al dilema veracidad versus primicia cuando se encuentran ante un hecho noticioso recientemente conocido o revelado y que, por lo tanto, puede estar sujeto a reservas.

Después de reunir el corpus, se recopilaron todos los titulares con condicional simple y compuesto. Posteriormente, se extrajeron todos los casos de condicionales periodísticos si- 
guiendo los parámetros de identificación de Vatrican (2016), antes expuestos. Partiendo de estos datos, se procedió al análisis. La investigación, aunque con un aporte cuantitativo, es, sobre todo, cualitativa, consistente en la descripción detallada de algunos ejemplos representativos.

Sin embargo, antes de seguir, conviene señalar que el motivo de elección de estas secuencias periodísticas tiene que ver con el importante papel que ha adquirido este espacio periodístico en la arquitectura hipertextual de los cibermedios, por lo que se habla ya de una función intertextual de estos (Salaverría 2005, 80), que vendría a sumarse a las otras funciones del periodismo tradicional (identificativa, informativa y apelativa) ${ }^{7}$. Así, el concepto de titular cobra especial relevancia en el discurso digital, porque no solo es el elemento que se halla en la superficie, el más visible y el primero accesible, sino que también es el nivel originario que dará paso a otros más profundos y la cúspide de toda una serie de bifurcaciones internas e, incluso, externas. A este hecho hay que unir otras dos razones: primero, los titulares constituyen las únicas secuencias leídas por gran parte de los consumidores de diarios, como se demostró hace tiempo y se sigue manteniendo en estudios recientes; segundo, por su misma naturaleza, los titulares periodísticos definen la interpretación del texto, sin olvidar que este espacio periodístico está sujeto a restricciones discursivas específicas que representan respuestas pragmáticas a una serie de factores que concurren en la enunciación: restricciones de espacio, contigüidad con el texto que encabeza, conocimientos previos que se suponen en el lector, periodicidad de la publicación, ideología del medio informativo y del lector, etc. En consecuencia, son el componente estratégico de los textos periodísticos.

\section{RESULTADOS Y DISCUSIÓN}

\subsection{Frecuencia de uso}

En la siguiente tabla se muestra la frecuencia (absoluta y relativa) del condicional periodístico en el corpus objeto de estudio.

Tabla 1. Frecuencia absoluta y relativa del condicional periodístico en el corpus de referencia

\begin{tabular}{|c|c|c|}
\hline Corpus & Frecuencia absoluta & Frecuencia relativa \\
\hline La Nación (Argentina) & 31 & $22,3 \%$ \\
\hline El Tiempo (Colombia) & 27 & $19,4 \%$ \\
\hline El Mercurio (Chile) & 22 & $15,9 \%$ \\
\hline La República (Perú) & 21 & $15,1 \%$ \\
\hline El Nacional (Venezuela) & 10 & $7,2 \%$ \\
\hline El Mundo (España) & 10 & $7,2 \%$ \\
\hline El País (España) & 6 & $4,3 \%$ \\
\hline El Universo (Ecuador) & 6 & $4,3 \%$ \\
\hline El Universal (México) & 6 & $4,3 \%$ \\
\hline Total & 139 & $100 \%$ \\
\hline
\end{tabular}

7 Aunque no entremos aquí en muchos detalles, no faltan ni las definiciones ni las clasificaciones de los titulares de prensa, tanto en los trabajos de investigación lingüística como en los manuales de redacción periodística. 
De las 360 noticias que conforman el corpus, son 145 los títulos que presentan un condicional en su formulación y, de ellos, 139 pueden interpretarse como casos de condicional periodístico (simple o compuesto): el 95,9 \% (139/145) en relación con todos los títulos en condicional y el 38,6 \% de todos los titulares (139/360). Por lo tanto, se confirma que el condicional periodístico es un valor recurrente en este espacio periodístico privilegiado. Siquiera en su forma simple, aparece documentado en toda la prensa hispánica, pero no se encuentra repartido de forma homogénea en el corpus. Hay que destacar la mayor presencia de los titulares con condicional periodístico (simple o compuesto) en determinados periódicos hispanoamericanos. El diario que muestra la frecuencia más alta de este tipo de titulares es La Nación, de Argentina, con un 22,3 \% de casos (31/139). Le sigue el periódico El Tiempo, de Colombia, con un porcentaje del 19,4\% (27/139) y, tras este, se sitúa El Mercurio, de Chile, con el 15,9 $\%$ (22/139) y La República, de Perú, con el 15,1 \% (21/139). A mayor distancia, hay que situar El Nacional, de Venezuela, con el 7,2 \% (10/139), porcentaje coincidente con El Mundo, de España. El otro periódico español muestra unas cifras idénticas a las de los periódicos de Ecuador y México, por lo que el porcentaje es el mismo para estos tres periódicos: 4,3 \% (6/139).

Sin embargo, la forma compuesta del condicional periodístico está muy poco representada, ya que solo se ha podido documentar en tres de los periódicos analizados: El Tiempo (Colombia), La Nación (Argentina) y El Universal (México), con tres casos en cada uno de ellos; su porcentaje de aparición apenas alcanza el 6,5\% (9/139), mientras que el condicional simple asciende al 93,5\% (130/139).

En definitiva, las frecuencias más altas son las correspondientes a la prensa de Argentina, Colombia, Chile y Perú, en consonancia con lo señalado por Seco (1998), mientras que los porcentajes más bajos se registran tanto en uno de los periódicos españoles analizados como en los diarios de Ecuador y México. A la vista de estos datos, se puede sostener que el condicional periodístico, en general, aparece con mayor frecuencia en la prensa de Hispanoamérica mientras que en la prensa peninsular es mucho menos frecuente titular de esta forma.

Por su parte, Kronning (2015), utilizando corpus periodísticos comparables (nueve diarios peninsulares y otros nueve hispanoamericanos), opone en bloque esta prensa y la de España. Según sus datos, la frecuencia para el valor del condicional epistémico de atribución es, en el caso de la prensa peninsular, del $37 \%$ (20/54), mientras que, para la prensa hispanoamericana, es del $87 \%$ (42/48), si bien las cifras totales que le sirven para calcular esos porcentajes son todas las ocurrencias de las formas del condicional (simple y compuesto) estaría, habría en títulos de la prensa escrita y/o electrónica publicados por Google Noticias durante un mes en 2012. Así, llega a la conclusión de que "la variación diatópica entre el español peninsular y el español de América es particularmente importante en el discurso periodístico paratextual de los títulos" (Kroning 2015: 514).

\subsection{Análisis de ejemplos}

Un aspecto que debe ser resaltado es que, en nuestro corpus, constituido, como ya hemos dicho, por artículos informativos pertenecientes a diferentes secciones temáticas, la mayor frecuencia de aparición de títulos con condicional periodístico se concentra en los artículos de carácter científico. Esto es así porque, en el caso de los descubrimientos en el campo de la ciencia o de la salud, la actividad es tan vertiginosa que el periodista se ve impelido a dar cuenta de acontecimientos que todavía no se han podido demostrar. 
Los siguientes enunciados remiten, por la posición que ocupan dentro del periódico, a la fracción conocida como titular o título, y el condicional periodístico que contienen indica tanto que la información expresada ha sido recibida de una fuente externa como que el periodista no se hace cargo de su veracidad:

(10) Los sapos podrían pronosticar los terremotos (La Nación, Argentina, 31/03/2010)

(11) Los sapos podrían predecir terremotos (La República, Perú, 30/03/12)

(12) Los sapos podrían anticipar los terremotos, según científicos británicos (El Tiempo, Colombia, 26/4/2010)

(13) Los sapos podrían anticipar terremotos, según científicos (El Universo, Ecuador, $31 / 3 / 2010)$

(14) Sapos podrían pronosticar terremotos, según estudio (El Universal, México, 31/3/2010)

Se observa que el condicional periodístico en los títulos puede aparecer solo (en el sentido de sin indicación explícita de la fuente de información) o junto con la expresión explícita de dicha fuente indicada mediante la expresión según $X$. Ahora bien, con respecto a esta, hay que destacar el empleo de expresiones formularias muy generales que aportan escasa o nula información. Es decir, las expresiones que aparecen en los anteriores titulares de la misma noticia (según científicos británicos, según científicos y según estudio), en realidad, no le permiten al receptor del periódico saber mucho más que antes sobre el origen de la información transmitida, pues, cuando no se trata de una percepción directa, como es el caso, siempre hay una fuente que proporciona los contenidos informativos (Henneman, 2013, 509). Por lo tanto, el grado de relevancia de este tipo de expresiones en la titulación es muy pequeño, ya que no permiten respaldar la información ofrecida, aparte de que este modo (tan vago) de identificar la fuente por parte del periodista puede influir en la credibilidad de la información. Por lo tanto, estas formulaciones sobre el origen de la información impresa han de interpretarse únicamente desde la perspectiva del periodista, que las emplea únicamente para distanciarse del contenido del enunciado. Así, parece ser que todo lo que hace el periodista para no tener que asumir la responsabilidad sobre las informaciones es el recurrir a una fuente "no identificada", pero el valor probatorio o evidencial de las expresiones evidenciales parece estar minimizado porque el receptor, como hemos dicho anteriormente, no sabe más que hay / había una "fuente" de la información transmitida.

Otro dato que se desprende del corpus y que, asimismo, se puede observar en los titulares anteriores, es la manifestación recurrente del condicional periodístico por medio de la forma podría seguida de un infinitivo. Este hecho también ha sido señalado por Álvarez (2004), quien destaca que de quince casos de condicional de rumor o periodístico, seis son oraciones con podría más infinitivo. Como el inglés permite utilizar el auxiliar could para expresar que se trata de algo no consumado, esta investigadora supuso, en un principio, que la incidencia de este tipo de oraciones podría ser mayor en la prensa hispana estadounidense, pero Álvarez descubrió precisamente lo contrario: la incidencia del condicional periodístico es muchísimo menor en la prensa digital hispana de los Estados Unidos. 
Ya Lapesa (1977: 227) advirtió que, cuando se usa podría con la interpretación de condicional periodístico (condicional de información no asegurada, como él llama a este uso), la semejanza con el de conjetura es mucho más visible. Por eso hay que ir con cuidado en la lectura que se hace de estos títulos, ya que no solo pueden llegar a confundirse con el condicional de conjetura, sino que, si no tenemos en cuenta el resto de la noticia, esta forma verbal puede resultar ambigua. En efecto, el caso de poder es complicado, porque en la forma podría no está muy claro el límite con los significados epistémico-modales, ya que el verbo poder, en sí, ya expresa modalidad epistémica.

En último lugar, hacemos referencia al funcionamiento discursivo de las noticias que se titulan con condicional periodístico. Esta forma verbal puede ser sustituida por otra distinta en el resto de componentes de la información. Lo vemos:

(15) Twitter podría propiciar una utilización inadecuada de los antibióticos (El Mundo, España, 31/3/2010) / Tienen sus buenos y malos usos. Las redes sociales en Internet, como Twitter o Facebook, pueden dificultar la utilización adecuada de los antibióticos. O al menos eso aseguran investigadores de la Universidad de Columbia (EE.UU.) y Mixedink.

(16) Las pastillas anticonceptivas podrían alargar la vida (La Nación, Argentina, 12/3/2010) / Según un estudio de la Aberdeen University of Escocia, las mujeres que prefieren ese método pueden vivir más tiempo y tienen menos posibilidades de morir de cáncer o enfermedades cardíacas.

(17) Un desayuno rico en grasas podría ser bueno para mantener un metabolismo sano ( $L a$ Nación, Argentina, 31/3/2010) / Un estudio realizado por la Universidad de Alabama, Estados Unidos, sustenta que realizar un desayuno rico en grasas y una cena ligera favorece la estabilidad del perfil metabólico y evita ganar peso.

Se observa que el condicional de los títulos (podría propiciar, podrían alargar, podría ser) se cambia, en el cuerpo del texto, por la perífrasis verbal en presente (pueden dificultar, pueden vivir) o por una forma verbal en presente más asertiva (favorece), seguidas de la expresión de la fuente de información por medio de la formulación más común (según $X$ ) o por otros marcadores de información relatada (al menos eso aseguran ..., por ejemplo).

Sin embargo, otra opción es que la forma en condicional del título vuelva a aparecer en el cuerpo del texto de la noticia:

(18) Fármaco Thalidomina podría combatir desorden en vasos sanguíneos (El Universo, Ecuador, 6/4/2010) / El fármaco Thalidomina, que causó defectos de nacimiento en el momento de su lanzamiento hace medio siglo cuando era utilizado como píldora para contrarrestar el malestar matinal, ahora podría ser útil para tratar una enfermedad hereditaria que afecta los vasos sanguíneos, dicen científicos.

(19) Lluvias ligeras podrían ocurrir el resto de la semana (La Nación, Argentina, 3/3/2010) / Las lluvias que cayeron en parte del territorio nacional [...] no significan el inicio de la temporada de lluvias, pero sí se podrían esperar precipitaciones ligeras a lo largo del mes de abril, de acuerdo con informaciones de Mario Iacobari, pronosticador del Instituto Nacional de Meteorología e Hidrología. 
Pero, siguiendo con el análisis contrastivo de los distintos elementos de la noticia, lo que no resulta admisible, desde el punto de vista de la coherencia textual, es que el periodista reconvierta, a la hora de titular, un modo de atribución con reservas en un modo de atribución directo por medio de la elección del presente de indicativo, forma verbal que conlleva un compromiso por parte del periodista con la verdad de lo aseverado. Esto es, lo que hay que evitar son incongruencias de sentido como las siguientes:

(20) Excesivo consumo de té verde provoca insomnio y ansiedad (La República, Perú, 4/4/2010) / La nutricionista Zulema Gallardo del Instituto Nacional de Salud del Niño indica que consumir té verde en cantidades mayores podría causar insomnio y ansiedad en quienes las ingieren desmedidamente.

El presente en el titular, sin atribución además a ninguna fuente, puede constituir una estrategia pragmática por parte del redactor con el fin de atraer al lector, pero, al fin, como es distinto el grado de certeza con el que se entrega la información en la noticia, su lectura, como mínimo, provoca desconcierto en los lectores. No hay que olvidar que en las noticias científicas el periodista cumple la función de mediador entre el ámbito de la ciencia y el mundo cotidiano del lector, por lo que transmitir como un hecho aquello que es una información no asegurada puede ciertamente tener consecuencias negativas en los receptores de la información, debido a que genera falsas expectativas y desconfianza.

\section{CONCLUSIONES}

La primera conclusión de este trabajo se refiere a la variación diatópica del condicional periodístico en la prensa digital de habla hispana. En líneas generales, este condicional (simple o compuesto) presenta porcentajes de frecuencia más altos en Hispanoamérica que en España. En concreto, las cifras más elevadas corresponden a la prensa de Argentina, Colombia, Chile y Perú. Tanto en el resto de periódicos hispanoamericanos examinados (de Venezuela, Ecuador y México) como en los peninsulares, el porcentaje de ocurrencias es mucho más bajo. Esto es así, especialmente, en el caso del condicional compuesto, cuya presencia en el corpus es escasa.

Dado que en el caso de los textos periodísticos es obvio que gran parte de la información se obtiene indirectamente, su presencia en el discurso periodístico (focalizado en este trabajo en el titular) es alta; por eso mantiene una relación muy estrecha con el género en el que aparece y contribuye a configurar la construcción discursiva en la prensa.

Por otra parte, cuando este condicional aparece en la titulación periodística, observamos los dos valores esperables: la alusión a la palabra ajena y la presentación de la información como no segura (aunque con variados matices según los casos: prudencia, más o menos probable, como asegurada pero requiere de una etapa posterior para su concreción, simple reserva, etc.). Por ello este condicional resulta ser una forma apropiada para titular informaciones de carácter científico, ya que las propiedades inherentes a este tipo de noticias hacen que la selección de esta forma, a la hora de titular, esté justificada. Asimismo, puede aparecer, conservando los dos valores mencionados, sin el auxilio de estructuras sintácticas o léxicas ad hoc o bien con la expresión explícita de la fuente de información, que, en el caso de que aparezca, debido al carácter resumido y sintético de esta fracción de la noticia, 
se formula mediante expresiones vagas y, por lo tanto, poco informativas, del tipo según $X$. Sin embargo, dado que en el texto contiguo se detallan las fuentes, presuponemos que el periodista no tiene ningún interés especial en ocultar el origen de la información. Se trata, más bien, de la actitud que adopta el periodista en relación con la fiabilidad de la información transmitida $\mathrm{y}$, al fin, se constituye en una estrategia comunicativa fundamental.

Cabe señalar, además, la abundante presencia del verbo modal poder entre las ocurrencias del condicional, si bien, en lo que se refiere a las formas condicionales del verbo poder, parece mucho más difícil indicar con seguridad el valor de estas ocurrencias, dada la naturaleza misma de este verbo modal. De hecho, es perceptible el valor evidencial de poder, pero al mismo tiempo el límite entre este valor y el estrictamente modal no está del todo claro. Aquí se nota muy claramente la cuestión, que todavía no ha sido resuelta, de la relación entre modalidad y evidencialidad, y la dificultad para definir hasta qué punto se puede hablar de convergencia entre estos dos dominios.

Asimismo, el condicional periodístico puede presentar enfoque de pasado o de futuro (para la forma simple) y de pasado (para la forma compuesta) y siempre aparece en frases declarativas en tercera persona.

En cuanto al funcionamiento discursivo del condicional periodístico dentro del texto en su conjunto, hay que decir que este puede mantenerse en el cuerpo de la noticia, pero también es muy frecuente que sea sustituido por la forma verbal en presente, aunque seguida de los marcadores de información relatada (incluido según X). También hemos observado algún caso de disimetría titular-noticia en el sentido de que en el titular aparece una forma verbal en presente, mientras que en la narración de la noticia aparece el condicional periodístico. Si bien es obvio que el titular es una forma peculiar de filtrar la realidad, este tipo de incoherencias no responde al concepto de seriedad y rigor de los periódicos analizados.

En resumen, a pesar de las evidentes limitaciones de un estudio de estas características (con un corpus limitado y restringido a una muestra de textos escritos periodísticos), con este trabajo creemos haber aportado información interesante y nuevas vías de análisis sobre el uso del condicional periodístico en los titulares de habla hispana.

\section{REFERENCIAS BIBLIOGRÁFICAS}

Aikhenvald, A. (2004). Evidentiality. Oxford: Oxford University Press.

Álvarez, I. (2004). "El español virtual en Estados Unidos: estudio de la lengua usada por la prensa en Internet”, Español Actual, 81, pp. 55-68.

Azzopardi, S. (2013). "Valor aspectuo-temporal y usos modales del condicional a la luz de la noción de gramaticalización”. En Cabedo Nevot, A., M. Aguilar Ruiz y E. López-Navarro Vidal (eds.). Estudios de lingüistica: investigaciones, propuestas y aplicaciones. Valencia: Tecnolingüística, pp. 337-347.

Bermúdez, F. (2006). Evidencialidad. La codificación lingüística del punto de vista. Estocolmo: Universidad de Estocolmo: http://www.diva-portal.org/smash/get/diva2:199511/FULLTEXT01.pdf (31-032020).

Bermúdez, F. (2016). "Rumores y otros malos hábitos. El condicional evidencial en español”, Cuadernos de lingüística de El Colegio de México, 3, 2, pp. 35-69. DOI: http://dx.doi.org/10.24201/clecm. v3i2.37.

Borrego Nieto, J. (dir.). Cocodrilos en el diccionario. Barcelona: IE/Espasa 
Brunetti, P. (2016). "El condicional de rumor o periodístico. Usos, funciones y algunos problemas", El Cactus. Revista de Comunicación, 5, 5, pp. 108-114.

Casado Velarde, M. (1995). "El lenguaje de los medios de comunicación”. En Seco, M. y G. Salvador (eds.). La lengua española hoy. Madrid: Fundación Juan March, pp. 153-164.

Foullioux, C. (2006). "Los valores del condicional en francés y su comparación con el español", Thélème. Revista Complutense de Estudios Franceses, 21, pp. 63-79.

García Negroni, M. M. (2018). "Argumentación y puntos de vista evidenciales: acerca del condicional citativo en el discurso periodístico y en el discurso científico", Boletín de Lingüística, 30, 49-50, pp. 86-109.

Gili Gaya, S. (1943). Curso superior de sintaxis española. Barcelona:Vox.

Hennemann, A. (2013). "Siempre habla 'una fuente': el (ab)uso de los marcadores evidenciales por los periodistas". En Casanova, E. y C. Calvo Rigual (coords.). Actas del XXVI Congreso Internacional de Lingüística y Filología Románicas, 5, pp. 505-515.

Kronning, H. (2014). "Pour une linguistique contrastive variationelle: le conditionnel épistémique d' 'emprunt' en français, en italien et en espagnol". En Helland, H. P. y C. Meklenborg Salvesen (eds.). Affaire(s) de grammaire. Mélanges offerts à Marianne Hoboek Haff à lóccasion de ses soixante-cinq ans. Oslo: Novus, pp. 67-90.

Kronning, H. (2015). “El condicional epistémico ‘de atribución' en francés, italiano y español: aspectos diafásicos, diatópicos y diacrónicos”. En Kragh, Kirsten, J. y J. Lindschouw (eds.). Les variations diasisytématiques et leurs interdépendances dans les langues romanes. Estrasburgo: Éditions de lingusitique et de philologie, pp. 507-518.

Lapesa, R. (1977). “Tendencias y problemas actuales de la lengua española”. En Lapesa, R. (coord.). Comunicación y lenguaje. Madrid: Karpos, pp. 203-229.

Lázaro Carreter, F. (2001). El dardo en la palabra. Barcelona: Galaxia Gutenberg.

Nadal Palazón, J. (2012). "Rasgos formales de los titulares periodísticos: notas sobre diez diarios del ámbito hispánico", Acta poética, 33, 1, pp. 173-195.

Real Academia Española y Asociación de Academias de la Lengua Española (2009). Nueva gramática de la lengua española. Madrid: Espasa.

Reyes, G. (1994). Los procedimientos de cita: citas encubiertas y ecos. Madrid: Arco Libros.

Ridruejo, E. (1979). "La forma verbal en -ra en el español del siglo XIII (oraciones independientes"), Cuadernos de investigación filológica, 5, pp. 23-28.

Rojo, G. y A. Veiga (1999). "El tiempo verbal. Los tiempos simples". En Bosque, I y V. Demonte (dirs.). Gramática descriptica de la lengua española. Madrid: Espasa, pp. 2867-2934.

Salaverría, R. (2005). Redacción periodística en Internet. Pamplona: Eunsa.

Seco, M. (1998). Diccionario de dudas y dificultades de la lengua española. Madrid: Espasa Calpe.

Vatrican, A. (2014). "Usos y valores modales del condicional en español", Archivum, 64, 239-274.

Vatrican (2016). El condicional en español, Madrid, Arco/Libros.

Veiga, A. (1991). Condicionales, concesivas y modo verbal en español. Santiago de Compostela: Universidad de Santiago de Compostela. 